\title{
EFEITO DA UTILIZAÇÃO DE PRÓBIÓTICOS EM DIETAS PARA BOVINOS NELORE TERMINADOS EM CONFINAMENTO
}

\author{
EFFECT OF PROBIOTICS INCLUSION IN DIETS FOR NELLORE CATTLE \\ FINISHED IN FEEDLOT
}

E. C. RIGOBELO ${ }^{1}$, O. R. MACHADO ${ }^{2}$, M. V. CARDOZO ${ }^{3}$

\begin{abstract}
RESUMO
O objetivo do presente trabalho foi avaliar se o probiótico $\mathrm{DBR}^{\circledR}$ pode substituir a monensina sódica na alimentação de bovinos em confinamento. Foram utilizados 18 bovinos da raça Nelore, com média de idade de 18 meses e $362 \pm 30 \mathrm{~kg}$ de peso vivo, no início do experimento. Os animais foram distribuídos em baias individuais cobertas, com acesso a sombra e água, em um delineamento inteiramente casualizado. A alimentação foi fornecida ad libitum, duas vezes ao dia, às $8 \mathrm{~h}$ e $16 \mathrm{~h}$, com uma dieta a base de bagaço de cana-de-açúcar como fonte de volumoso (18\%) e concentrado (82\%), que apresentava 72,4\% de NDT e 14,2\% de PB. Além da dieta citada, os animais receberam diariamente $100 \mathrm{~g}$ de uma mistura contendo milho moído, pela qual foram fornecidas quantidades específicas de monensina sódica e $\mathrm{DBR}^{\circledR}$ Probiótico conforme os seguintes tratamentos: DBR (milho moído $+2,0 \mathrm{~g} \mathrm{DBR}^{\circledR}$ Probiótico); MON (milho moído + $275 \mathrm{mg}$ de monensina sódica) e DBR + MON (milho moído + 1,0g de DBR ${ }^{\circledR}$ Probiótico + 138mg de monensina sódica). Não foram verificados efeitos dos diferentes aditivos sobre o consumo de matéria seca, ganho de peso, eficiência, conversão alimentar e características da carcaça dos bovinos submetidos aos diferentes tratamentos dietéticos $(\mathrm{P}>0,05)$. Conclui-se que o $\mathrm{DBR}^{\circledR}$ probiótico pode substituir total ou parcialmente a monensina sódica em dietas com alta proporção de concentrados para bovinos Nelore em confinamento.
\end{abstract}

PAlaVRAS-CHAVE: Acidose. Aditivo probiótico. Carcaça de bovino. Consumo de matéria seca. Ganho de peso diário.

\section{SUMMARY}

The aim of this study was to evaluate if the DBR ® probiotic can replace monensin in cattle feed in confinement. Eighteen animals of Nellore breed were used, with an average age of 18 months and $362 \pm 30 \mathrm{~kg}$ live weight at the beginning of the experiment. The animals were distributed into individual pen, with access to shade and water, in a completely randomized design. Feed was provided ad libitum, twice daily at $8 \mathrm{am}$ and $16 \mathrm{~h}$, with a diet of crushed cane sugar as a source of roughage (18\%) and concentrate (82\%), which had $72.4 \%$ TDN and $14.2 \%$ CP). Besides the aforementioned diet, the animals received daily $100 \mathrm{~g}$ of a mixture containing corn, which were provided by specific amounts of sodium monensin and probiotic DBR ${ }^{\circledR}$ according to the following treatments: DBR (corn meal $+2.0 \mathrm{~g}$ of probiotic DBR ${ }^{\circledR}$ ); MON (corn meal $+275 \mathrm{mg}$ monensin sodium) and MON + DBR (corn meal $+1.0 \mathrm{~g}$ probiotic $\mathrm{DBR}^{\circledR}+138 \mathrm{mg}$ of sodium monensin). The aim of this work was evaluate whether Probiotic DRB could replace the monesin. Data were subjected to analysis of variance using the SAS statistical software. There were no effects of different additives on the dry matter intake, weight gain, efficiency, feed conversion and carcass characteristics of cattle subjected to different dietary treatments $(\mathrm{P}>0.05)$. We conclude that the probiotic $\mathrm{DBR}^{\circledR}$ can replace all or part of sodium monensin in diets with high levels of concentrates in feedlot for Nellore cattle.

KEY-WORDS: Acidosis. Probiotic additive. Average daily gain. Bovine carcass. Dry matter intake.

\footnotetext{
${ }^{1}$ Professor Assistente Doutor de Microbiologia Agrícola, Departamento de Produção Vegetal FCAV-UNESP Jaboticabal/SP. é: everlonnsms@fcav.unesp.br

${ }^{2}$ Pós Doutorando na área de bovino de corte Deto Zootecnia UFL, Lvras/MG.

${ }^{3}$ Doutoranda em Microbiologia Agropecuária do PPGM da FCAV-UNESP, Jaboticabal/SP.
} 


\section{INTRODUÇ̃̃O}

Atualmente tem sido verificado um crescente aumento na terminação de bovinos em confinamento, com grande número de animais alojados por ciclo de engorda, o que cria a necessidade de aumento na inclusão de alimentos concentrados nessas dietas, uma vez que altas proporções de alimentos volumosos podem inviabilizar a prática do confinamento devido à grande área necessária para a produção destes alimentos. Como consequência do aumento da concentração energética das dietas por meio da maior inclusão de concentrados, observa-se maiores riscos relacionados à saúde ruminal dos animais submetidos a este manejo alimentar.

Para que sejam evitados distúrbios digestivos como a acidose ruminal, a inclusão de aditivos modificadores da fermentação ruminal torna-se obrigatória. A monensina sódica é o principal aditivo utilizado com este propósito. Este aditivo tem sido utilizado na alimentação de bovinos de corte por mais de 20 anos para aumentar a eficiência alimentar, entretanto, tem sido crescente a busca na comunidade cientifica por aditivos que possam substituir a monensina, pois substãncias sintéticas estão sendo cada vez mais rejeitadas pelos produtores e consumidores de produtos de origem animal. Entre várias substâncias naturais, os probióticos podem trazer os benefícios da monensina, com a grande vantagem de ser um produto autorizado, que não deixa resíduos na carne e também não causa prejuízos para o consumidor final (GOODRICH et al., 1984; RUSSELL e STROBEL, 1989).

Os probióticos podem ser compostos por bactérias ou leveduras, e as leveduras têm sido amplamente utilizadas na dieta de bovinos de corte pois promove grandes melhorias no desempenho animal em relação a outros aditivos. Esses microrganismos estimulam a microflora ruminal, pois quando presentes no rúmen, as leveduras produzem fatores que aumentam a atividade e o crescimento das bactérias ruminais, principalmente das celulolíticas. Com isso, ocorre aumento da taxa de degradação ruminal e da digestibilidade da fibra Além disso, as leveduras mantêm o pH ruminal e são muito eficientes da redução da concentração de oxigênio no rúmen, que é essencial para o crescimento dos microrganismos anaeróbios e também reduz a adesão da fibra pelas bactérias celulolíticas (Newbold et al., 1996, Gattas, 2005).

Estes motivos contribuem para o maior consumo e melhor aproveitamento da dieta pelos animais, pois ocorre aumento da eficiência de utilização dos nutrientes no rúmen, alterando positivamente o metabolismo do animal e determinando melhores resultados no desempenho produtivo, evidenciando a importância de estudos com leveduras na dieta de bovinos.

Diante do exposto, o objetivo deste trabalho foi avaliar o efeito do $\mathrm{DBR}^{\circledR}$ Probiótico sobre $\mathrm{O}$ desempenho e características de características de carcaça de bovinos Nelore confinados, na fase terminação, com dietas contendo alto teor de concentrado.

\section{MATERIAL E MÉTODOS}

Foram utilizados 18 bovinos da raça Nelore, com média de idade de 18 meses e $362 \pm 30 \mathrm{~kg}$ de peso vivo, no início do experimento. Os animais foram distribuídos aleatoriamente, em um delineamento inteiramente casualisado, em baias individuais cobertas, com acesso a sombra e água.

A alimentação foi fornecida ad libitum, duas vezes ao dia, às $8 \mathrm{~h} 00$ e 16h00, com uma dieta a base de bagaço de cana-de-açúcar como fonte de volumoso (18\% da MS dietética) e concentrado (82\% da MS dietética) conforme descrito na Tabela 1. Para o cálculo das exigências nutricionais foi utilizado o Cornell Net Carbohidrate and Protein System - CNCPS (Fox, et al., 1992), de modo a atender à exigência de proteína degradável no rúmen e proteína bruta metabolizável, bem como a exigência de peptídeos das bactérias ruminais (Tabela 1), com um ganho de peso médio estimado de $1,41 \mathrm{~kg} / \mathrm{dia}$.

Além da dieta citada, os animais receberam diariamente $100 \mathrm{~g}$ de uma mistura contendo milho moído, pela qual foram fornecidas quantidades específicas de monensina sódica e $\mathrm{DBR}^{\circledR}$ Probiótico conforme os tratamentos a seguir: MON (milho moído + 275mg de monensina sódica), DBR (milho moído + 2,0g de $\mathrm{DBR}^{\circledR}$ Probiótico), DBR+MON (milho moído $+1,0 \mathrm{~g}$ de $\mathrm{DBR}^{\circledR}$ Probiótico + 138mg de monensina sódica). $\quad \mathrm{O} \quad \mathrm{DBR}^{\circledR}$ Probiótico contém em sua composição os seguintes microrganismos por $\mathrm{Kg}$ de produto: Ruminobacter amylophilum (3,0 x $10^{11}$ UFC),

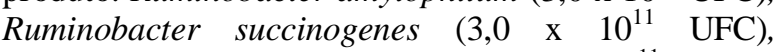
Succinovibrio dextrinosolvens $\left(4,4 \times 10^{11}\right.$ UFC), Bacillus cereus (3,5 x $10^{11}$ UFC), Lactobacillus acidophilus (3,5 x $10^{11}$ UFC), Streptococcus faecium $\left(3,5 \times 10^{11}\right.$ UFC). As doses fornecidas aos animais seguiram as recomendações do fabricante.

As misturas foram preparadas em misturador com capacidade de $100 \mathrm{~kg}$ e então foram acondicionadas em sacos plásticos, devidamente identificados, na quantidade a ser fornecida ao animal $(100 \mathrm{~g})$.

Durante os primeiros 15 dias após a chegada ao local do estudo, os animais foram adaptados ao local e à dieta. Neste período os animais receberam uma mistura de bagaço de cana crú e silagem de milho à vontade e ração concentrada na quantidade de 2,0 $\mathrm{kg} / \mathrm{animal}$ nos dias 1 a 5; 4,0 kg/animal nos dias 6 a 10 e 6,0 kg/animal entre os dias 11 e 15 da adaptação. Esta fase não foi computada para fins de cálculo de consumo de alimentos e ganho de peso dos animais. As misturas com aditivos não foram fornecidas nesta fase.

Os animais foram separados aleatoriamente em três tratamentos dietéticos, sendo seis repetições por tratamento. $\mathrm{Na}$ fase de avaliação, as misturas entre milho moído e os aditivos foram fornecidos juntamente com a ração da manhã e na dieta da tarde com o objetivo de garantir o consumo integral das misturas contendo os aditivos. 
Tabela 1 - Composição de ingredientes e de nutrientes da dieta utilizada para ganho de peso corporal de $1,41 \mathrm{~kg} / \mathrm{cab} / \mathrm{dia}$.

\begin{tabular}{|c|c|}
\hline Ingredientes & $\%$ na MS \\
\hline Bagaço de cana in natura & 18,0 \\
\hline Milho grão seco & 42,5 \\
\hline Farelo de soja $49 \%$ & 7,0 \\
\hline Casca de soja peletizada & 30,0 \\
\hline Uréia & 1,0 \\
\hline Núcleo mineral ${ }^{1}$ & 1,5 \\
\hline \multicolumn{2}{|l|}{ Nutrientes avaliados $^{2}$} \\
\hline Proteína bruta, \% & 14,2 \\
\hline Proteína degradável no rúmen, \% & 9,05 \\
\hline $\mathrm{NDT}^{3}, \%$ & 72,4 \\
\hline FDN, $\%$ & 21,1 \\
\hline Extrato etéreo, \% & 2,8 \\
\hline $\mathrm{Ca}$ & 0,44 \\
\hline $\mathrm{P}$ & 0,29 \\
\hline
\end{tabular}

${ }^{1}$ N210 Agroceres Multimix: Composição por kg e produto - Ca: 160g; P: 24g, Mg: 5g; Na: 59,3g; S: 28g; Co: 8, 23mg; Cu: 560mg; I: 28mg; Mn: 1120mg; Se: 5,6mg; Zn: 1680mg; Vit A: 73920 UI; monensina: 1.000mg;

${ }^{2}$ Estimados a partir do programa CNCPS (Fox, et al., 1992);

${ }^{3}$ Estimado a partir da fórmula de Weiss et al. (1992).

O consumo de alimento (CMS) foi determinado diariamente sendo calculado como a diferença entre a quantidade de ração total fornecida e as sobras alimentares, as quais foram determinadas três vezes por semana. A quantidade de alimento fornecida foi ajustada de forma a manter $10 \%$ de sobras em relação ao total fornecido. Amostras de bagaço de cana e concentrado foram obtidas ao longo do período experimental para determinar o conteúdo de matéria seca da dieta e das sobras.

Os animais foram pesados, após jejum alimentar de $16 \mathrm{~h}$, no início e no final do período experimental e também a cada 28 dias. Durante as pesagens foram realizadas avaliações de carcaça através da ultrassonografia, para avaliação da área de olho de lombo e espessura de gordura subcutânea sobre a região entre as $12^{\mathrm{a}}$ e $13^{\mathrm{a}}$ costelas e sobre a garupa Para avaliação dessas características foi utilizado um equipamento de ultrassom, marca Aloka, modelo SSD 500 Micrus (Aloka Co. Ltd.), com transdutor linear de $3,5 \mathrm{mHz}$ e $172 \mathrm{~mm}$ de comprimento. As imagens foram armazenadas em um microcomputador portátil e posteriormente analisadas utilizando o software Lince ${ }^{\circledR}$ (M\&S Consultoria Agropecuária Ltda, Pirassununga, $\mathrm{SP}$, Brasil). O período experimental de avaliações teve duração de 84 dias.

O efeito dos tratamentos sobre as características de desempenho e de carcaça foram analisadas por análise de variância, através do procedimento General Linear Model do software SAS, versão 9.2 (SAS Institute Inc., Cary, NC, EUA) considerando o tratamento como efeito fixo. Foi adotado um nível de significância de $5 \%(\mathrm{P} \leq 0,05)$.

\section{RESULTADOS E DISCUSSAO}

Os resultados referentes ao consumo, desempenho, eficiência alimentar e características das carcaças dos bovinos alimentados com $\mathrm{DBR}^{\circledR}$ Probiótico e ionóforos estão descritos nas Tabelas 1 e 2. Em relação ao consumo de matéria seca, não foram observados efeitos dos tratamentos dietéticos sobre esta variável $(\mathrm{P}>0,05)$, evidenciando que os aditivos utilizados nas dietas experimentais produziram efeitos semelhantes sobre a ingestão de matéria seca. Por este motivo, o aditivo $\mathrm{DBR}^{\circledR}$ Probiótico pode ser utilizado em substituição à monensina sódica sem afetar o desempenho animal.

Considerando que o consumo de matéria seca é a principal variável que afeta o desempenho animal em sistemas de confinamento, o manejo correto da dieta por meio da eficiente adaptação dos animais, principalmente quando são utilizadas dietas com alta proporção de concentrado, como a do presente experimento, tem extrema importância sobre o desempenho e eficiência alimentar dos animais não somente durante a fase de adaptação, mas também durante todo o período de terminação (BRETHOUR, 2002). No rúmen, leveduras vivas parecem elevar o consumo, por aumentarem a taxa de degradação da fibra, causando aumento expressivo no número de bactérias anaeróbias e maior estabilidade do ambiente ruminal, reduzindo-se as variações diurnas de $\mathrm{pH}$, amônia e ácidos graxos voláteis (HUBER et al., 1994; WALLACE, 1994). 
Tabela 2 - Consumo, desempenho e eficiência alimentar de bovinos Nelore alimentados com DBR ${ }^{\circledR}$ Probiótico e ionóforos.

\begin{tabular}{|c|c|c|c|c|}
\hline & DBR & $\mathrm{MON}$ & $\mathrm{DBR}+\mathrm{MON}$ & Valor P \\
\hline GMD 0-28 dias & 2,30 & 1,95 & 2,00 & 0,5696 \\
\hline GMD 28-56 dias & 1,76 & 2,20 & 2,11 & 0,1833 \\
\hline GMD 56-84 dias & 1,77 & 1,99 & 1,81 & 0,5594 \\
\hline GMD 0-84 dias & 1,94 & 2,05 & 1,86 & 0,5039 \\
\hline CMS (Kg/dia) & 10,8 & 11,3 & 10,6 & 0,6219 \\
\hline EA (GPD/Kg MS) & 0,181 & 0,176 & 0,182 & 0,8543 \\
\hline
\end{tabular}

GMD 0-28 dias: Ganho de peso médio diário durante os primeiros 28 dias do período experimental; GMD 28-56 dias: Ganho de peso médio diário do $28^{\circ}$ ao $56^{\circ}$ dia experimental; GMD 0-56 dias: Ganho de peso médio diário do $56^{\circ}$ ao $84^{\circ}$ dia experimental. GMD 0 84 dias: Ganho de peso médio diário durante todo o período experimental. CMS: Consumo de matéria seca durante todo o período experimental; EA: Eficiência alimentar durante todo o período experimental.

Tabela 3 - Características de carcaça de bovinos Nelore alimentados com DBR ${ }^{\circledR}$ Probiótico e ionóforos.

\begin{tabular}{lcccc}
\hline & DBR & MON & DBR+MON & P \\
\hline PVi & 359 & 368 & 361 & 0,8733 \\
PVf & 521 & 532 & 526 & 0,8801 \\
RCQ & 54,17 & 53,52 & 52,68 & 0,1942 \\
PCQ & 292,9 & 291,53 & 285,21 & 0,8495 \\
EGS & 3,90 & 5,31 & 4,38 & 0,7383 \\
EGP & 6,40 & 6,63 & 6,38 & 0,9813 \\
\hline
\end{tabular}

PVi: Peso vivo inicial; PVf: Peso vivo final; RCQ: Rendimento de carcaça quente; PCQ: Peso de carcaça quente; EGS: Espessura de gordura subcutânea; EGP: Espessura de gordura na garupa

Dietas com alta concentração energética, como a utilizada no presente experimento, podem promover queda do $\mathrm{pH}$ ruminal, o que deprime o crescimento de bactérias digestoras de fibra. Diante disso, a utilização de aditivos como o DBR $^{\circledR}$ Probiótico pode proporcionar a melhoria da digestibilidade da fração fibrosa da dieta. A utilização de aditivos que possam estimular o consumo de matéria seca no inicio da engorda confinada é de extrema importância para o sucesso da atividade, pois em muitas situações os animais que chegam ao confinamento são oriundos de sistemas de produção a pasto, recebendo dietas com baixa proporção de carboidratos não fibrosos e tem dificuldade de se adaptar às dietas com alta concentração energética, tipicamente utilizadas em confinamento atualmente.

No que diz respeito ao ganho de peso médio diário não foram verificados efeitos dos tratamentos dietéticos $(\mathrm{P}>0,05)$ sobre esta variável. Nos primeiros 28 dias de confinamento, observou-se uma taxa de ganho de peso nos diferentes tratamentos, que pode ser considerada bastante elevada (cerca de $2,0 \mathrm{~kg} / \mathrm{dia}$ ) $\mathrm{o}$ que pode ser justificado pelo fenômeno do ganho compensatório, comum em situações de confinamento no Brasil, uma vez que os animais provavelmente se encontravam em situação de restrição alimentar no período que antecedeu a engorda confinada, ou então submetido à dietas com altas proporções de alimentos fibrosos, que tem a capacidade de deprimir o consumo e consequentemente a taxa de ganho de peso. Já no período seguinte ( 28 a 56 dias de confinamento) ainda foram observadas altas taxas de ganho de peso, o mesmo ocorrendo quando avaliado o período final de engorda ou todo o período de confinamento ( 84 dias). Além dos efeitos de ganho compensatório, a elevada concentração energética das dietas $(72,4 \%$ de NDT) pode ter colaborado para este efeito observado.

Os aditivos experimentais também produziram efeitos semelhantes sobre as variáveis de eficiência (conversão alimentar e eficiência alimentar), ficando demonstrada mais uma vez que a substituição da monensina sódica por aditivos alternativos como o $\mathrm{DBR}^{\circledR}$ Probiótico pode permitir manutenção do ganho de peso diário e da eficiência alimentar dos animais que é observada com o uso da monensina sódica, que é utilizada quase que na totalidade dos confinamentos de bovinos de corte no Brasil. A inclusão do $\mathrm{DBR}^{\circledR}$ Probiótico permite melhorias no ambiente ruminal dos animais, reduzindo os efeitos negativos que a alta fermentabilidade da dieta pode produzir sobre este compartimento do trato digestivo (ÁVILA et al., 2000). A suplementação de leveduras parece ser capaz de reduzir a concentração de lactato no rúmen (WILLIAMS et al., 1991), talvez pela estimulação de 
bactérias utilizadoras de lactato ou pela limitação da produção de lactato por bactérias produtoras de ácido lático, através da competição por substrato (NISBET \& MARTIN, 1991; CHAUCHEYRAS et al., 1996). Já o fornecimento de monensina resulta em aumento da concentração de propionato no rúmen e redução das concentrações de acetato. A produção de metano também é diminuída com a inclusão da monensina e dessa forma, o teor de energia metabolizável das dietas é aumentado em virtude de melhorias na digestibilidade da MS e retenção de hidrogênio no ácido propiônico (GOODRICH et al., 1984).

As características de carcaça (peso e rendimento) dos animais também não foram afetadas pelos tratamentos dietéticos, no entanto, todos os animais apresentaram carcaças com peso superior a 17 arrobas, como preconizado pelo mercado atual (PEDROSO et al., 2004). Vários fatores afetam o rendimento de carcaça: genética, idade, sexo, nutrição e alimentação etc. Entre eles, o nível energético da dieta consumida apresenta-se de grande importância, já que a deposição de gordura corporal promove diferenças na quantidade e qualidade da carcaça produzida (FRANZOLIN et al., 2001). Os diferentes aditivos utilizados atualmente na nutrição de ruminantes apresentam poucos efeitos diretos sobre as características de carcaça, como já relatado em outros artigos. Gomes et al. (2009), realizaram experimento com o objetivo de avaliar o efeito da inclusão de monensina e levedura sobre a qualidade da carcaça de bovinos terminados em confinamento e concluíram que o fornecimento de monensina, levedura ou a associação de ambos na dieta não exerce efeitos importantes sobre características de carcaça e da carne. Os autores afirmam ainda que a inclusão destes aditivos não promovem melhorias em peso de carcaça, rendimento de carne na carcaça e no teor de gordura da carcaça, que é um indicativo do grau de marmoreio. Os principais benefícios da inclusão de aditivos em dietas de terminação residem na melhoria da eficiência alimentar dos animais e redução da incidência de distúrbios digestivos (ÁVILA et al., 2000), como já relatado. Entretanto, o efeito positivo que estes ingredientes produzem permite que os animais tenham maior taxa de ganho de peso, em virtude da redução da ocorrência de transtornos digestivos e consequentemente possam apresentar carcaças mais pesadas, como desejado pelo mercado.

A inclusão do aditivo DBR ${ }^{\circledR}$ Probiótico também promoveu efeitos semelhantes ao observado com a utilização de monensina sódica, tanto para o peso da carcaça quente quanto para o rendimento de carcaça. Para a área de olho de lombo (AOL) também não foram verificados efeitos das dietas experimentais sobre esta variável, entretanto os valores observados encontram-se dentro do preconizado por LUCCHIARI FILHO et al. (2000). A avaliação da AOL realizada no músculo Longissimus tem se mostrado diretamente ligada ao total de músculos na carcaça, enquanto a espessura de gordura subcutânea, diretamente ao total de gordura na carcaça e indiretamente à quantidade de músculos, uma vez que, quanto maior o acúmulo de gordura, menor a proporção de músculos (FORREST et al., 1975). Segundo MULLER (1980) e LUCCHIARI FILHO (2000) a espessura de gordura subcutânea desejável para uma boa conservação da carcaça deve ser de no mínimo $3 \mathrm{~mm}$. A falta de gordura de cobertura faz com que a carcaça dos bovinos, durante o resfriamento, desenvolva escurecimento da parte externa dos músculos, prejudicando o seu aspecto, além de encurtamento das fibras, que prejudica a maciez, depreciando o valor comercial. Em todos os tratamentos dietéticos a espessura de gordura subcutânea foi superior ao valor mínimo de $3 \mathrm{~mm}$. Assim como a espessura de gordura subcutânea, a espessura de gordura na garupa (EGP) pode ser utilizada como um indicador da gordura corporal da carcaça e diante dos resultados obtidos, pode-se afirmar que os animais que receberam os diferentes aditivos produziram carcaças com acabamento semelhante. A associação do probiótico com a monensina apresentou resultados em relação ao ganho de peso médio, consumo de matéria seca e eficiência alimentar, bem como de características das carcaças semelhantes quando comparados a utilização do aditivo e inóforo separadamente, entretanto, uma vez que a monensina apresenta restrições para exportação, não seria interessante utilizar essa associação.

\section{CONCLUSÃO}

A utilização do $\mathrm{DBR}^{\circledR}$ Probiótico produz efeitos semelhantes aos observados com a utilização do ionóforo monensina sódica. Diante deste fato é possível inferir que este aditivo pode substituir total ou parcialmente o ionóforo, que possui restrições de utilização para animais que terão a carne exportada para a União Européia.

\section{AGRADECIMENTOS}

Os autores agradecem o Prof. Dr. Saulo da Luz e Silva da Faculdade de Zootecnica e Engenharia de Alimentos da USP Pirassununga- SP, pela realização da parte experimental e estatística.

A IMEVE S/A pelo fornecimento do produto DBR Probiótico.

\section{REFERÊNCIAS}

ÁVILA, F. A.; PAULILlO, A. C.; SCHOCKENITURRINO, R. P.; LUCAS, F. A.; ORGAZ, A.; QUINTANA, J. L. Evaluation of efficiency of a probiotic in the control of diarrhea and weight gain in calves. Arquivo Brasileiro de Medicina Veterinária e Zootecnia, p.41-16, 2000.

BRETHOUR, J. R. Using serial ultrasound measures to generate models of marbling and backfat thickness changes in feedlot cattle. Journal of Animal Science, v.78, p.2055-2061, 2002.

CHAUCHEYRAS, F.; FONTY, G.; BERTIN, G.; SALMON, J. M.; GOUET, P. Effects of a strain of Saccharomyces cerevisiae (Levucell SC), a microbial additive for ruminants, on lactate metabolism 
in vitro. Canadian Journal of Microbiology, v.42, p.927-933, 1996.

FORREST, J. C. A.; ABERLE, E. D. A.; HEDRICK, H. B. Principles of meat science. San Francisco: W.H. Freeman, 1975, p.417.

FOX, D. G.; SNIFFEN, C. J.; O'CONNOR, J. D. A net carbohydrate and protein system for evaluating cattle diets: III Cattle requirements and diet adequacy. Journal of Animal Science, v.70, p.3578-3596, 1992.

FRANZOLIN, R.; SILVA, J. R.; OCAMPOS, D. Níveis de Energia na Dieta para Bubalinos em Crescimento Alimentados em Confinamento. Revista Brasileira de Zootecnia, v.30, n.6, p.1872-1879, 2001.

GATTAS, C. B. A. Influência da suplementação com cultura de levedura na digestibilidade, fermentação ruminal e ganho de peso de bovinos de corte. 2005. Campo Grande, 50f. Dissertação (Mestrado). Universidade Federal do Mato Grosso do Sul.

GOMES, R. C.; LEME, P. R.; SILVA, S. L.; ANTUNES, M. T.; GUEDES, C. F. Carcass quality of feedlot finished steers fed yeast, monensin, and the association of both additives. Arquivo Brasileiro de Medicina Veterinária e Zootecnia [online], v.61, n.3, p.648-654, 2009.

GOODRICH, R. D.; GARRETT, J. E.; GAST, D. R. Influence of monensin on the performance of cattle. Journal of Animal Science., v.58, p.1484-1498, 1984.

HUBER, J. T.; HIGGINBOTHAM, G.; GOMEZALRCON, R. A. Heat stress interactions with protein, supplemental fat, and fungal cultures. Journal of Dairy Science, v.77, p.2080-2090, 1994.

LUCHIARI FILHO, A. Pecuária da carne bovina. São Paulo: LinBife. 2000, p.134.

MÜLLER, L. Normas para avaliação de carcaças e concurso de carcaças de novilhos. Santa Maria: Imprensa Universitária/UFSM. 1980, p.31.

NEWBOLD, C. J; WALLACE, R. J; Mc INTOSH, F.M. Mode of action of the yast Scchacaromyces cerevisiae as feed additive for ruminants. British Journal of Nutrition, v.76, n.2, p.249-261, 1996.
NISBET, D. J.; MARTIN, S. A. Effect of a Saccharomyces cerevisiae culture on lactate utilization by the ruminal bacterium Selenomonas ruminantium. Journal of Dairy Science, v.69, p.46284633, 1991.

NISBET, D. J.; MARTIN, S. A. Effect of a Saccharomyces cerevisiae culture on lactate utilization by the ruminal bacterium Selenomonas ruminantium. Journal of Dairy Science, v.69, p.4628-4633, 1991.

PEDROSO, E. K.; PEDROSO, P. K.; LOCATELI, A. L.; GROSSKLAUS, C. Marketing e Cadeia Produtiva da Carne. In: IV SIMCORTE - Simpósio de Produção de Gado de Corte, 2004. Viçosa. MG. Brasil. 2004, p.145-166.

RUSSELL, J. B., STROBEL, H. J. The effect of ionophores on rumen fermentation. Applied of Environment Microbioogy., v.55, p.1-6, 1989.

SAS. SAS Institute Inc® 2003. Cary, NC, USA, Lic. UDESC: SAS Institute Inc, 2003.

WALLACE, R. J. Ruminal microbiology, biotechnology, and ruminant nutrition: progress and problems. Journal of Animal Science, v.72, p.29923003, 1994.

WEISS, W. P., CONRAD, H. R., PIERRE, N. R. A theoretical-based model for predicting total digestible nutrient values of forages and concentrates. Animal Feed Science and Technology, Amsterdam, v.39, p.95-110, 1992.

WILLIAMS, P. E. V.; TAIT, C. A. G.; INNES, G. M. e NEWBOLD, C. J. Effects of the inclusion of yeast culture (Saccharomyces cerevisiae plus growth medium) in the diet of cows on milk yield and forage degradation and fermentation patterns in the rumen of sheep and steers. Journal of Animal Science, v. 69, p.3016-3026, 1991. 